\title{
FabLab Barcelona-Co-design With Food Surplus: Better Redistributing, Upcycling and Composting
}

\author{
Marion Real, Anastasia Pistofidou, and Milena Juarez Calvos
}

The chapter analyses a co-designed project in the food value chain. Looking at how to identify and stimulate new synergies among the local community in order to codevelop educational, logistic and environmental supports for better redistributing, upcycling and composting food locally, it critically presents the case of a symbiotic system for food surplus and bio waste valorisation at a neighbourhood scale.

\section{Introduction}

IAACIFab Lab Barcelona is renowned as a key educational organisation in the Fab Lab Network since 2007 participating in the strategy and coordination of programs involving more than $1800 \mathrm{Fab}$ Labs worldwide. IAAC|Fab Lab Barcelona is promoting innovation for sharing and circular cities with a focus on education, community empowerment and seven strategic areas of expertise: Sense Making, Productive Cities, Materials and Textiles, Future Learning, Civic Ecology, Distributed Design, and Emergent Futures. They have a pioneering and original approach of co-creation at the crossroad between peer learning, citizen science [29], digital fabrication and distributed design, central to engage with local communities.

M. Real (更) · A. Pistofidou $\cdot$ M. Juarez Calvos

IAAC, Fab Lab Barcelona, Barcelona, Spain

e-mail: marion@fablabbcn.org
A. Pistofidou
e-mail: anastasia@fablabbcn.org
M. Juarez Calvos
e-mail: milena@ fablabbcn.org

(C) The Author(s) 2022

A. Deserti et al. (eds.), Co-creation for Responsible Research and Innovation, Springer Series in Design and Innovation 15,

https://doi.org/10.1007/978-3-030-78733-2_4 
This practice has been built along the years thanks to European projects especially like Making Sense, ${ }^{1}$ DDMP $^{2}{ }^{2} \operatorname{SCAPE}^{3}[6,14,16]$.

The co-creation journey in SISCODE started with the wish of creating a playground for atterizing the Fab City vision [5] into the locality of Barcelona, in the creative neighbourhood of Poblenou. Since 2019, the team explored how makerspaces such as fablabs can foster local transformations guided by circular community and distributed manufacturing principles. After a first contextual analysis, the local team could emphasise the importance of food and plastic waste in Catalunya and discover new design practices emerging from new bioeconomy trends [8]. They opted to address the issue of food waste creating synergies with the maker ecosystem, food stakeholders and organisations of civil society in the area.

Cycles of collective activities, individual coaching and access to infrastructure were proposed by the lab to support an emergent community group to learn, nest and co-produce new design practices with food waste. Named Remix El Barrio, is now defined as a collective of designers who propose projects with food leftovers using artisan techniques and digital manufacturing to foster circular transformations in Poblenou.

\section{Ecosystem, Context and Challenge Addressed}

Catalonia region and the city of Barcelona are the cradle of the Fab City network and many innovative practices related to bottom-up approaches, participative policy design processes and citizen-led platform like SmartCitizen, SuperBarrio and DECIDIM $^{4}$ [4]. As many cities and regions, they have also initiated the development of circular economy action plans [18]. The climate action (from 2018 to 2030) is highlighting actions for responsible consumption, zero waste and food sovereignty and dedicating a specific part for the design of new training programs in the circular economy [2]. Beyond that, they have been really active in the food-chain value transformation especially with the program of the World Capital of Sustainable Food 2021. Concerning food waste, an important and innovative law [1] has been signed in 2020 and a dynamic network of stakeholders is now operationalising the strategy with promising changes to accelerate a better valorisation of food cycles in territories.

When zooming in the territorial distribution, the crucial role played by the neighborhoods (aka barrio) in reconnecting people's intentions and communities to public institutions becomes visible [15]. The city originally introduced a plan for creating self-sufficient neighbourhoods and relevant solutions to empower citizens and face social struggles.

\footnotetext{
${ }^{1} \mathrm{http}: / /$ making-sense.eu/.

${ }^{2} \mathrm{https} / / /$ distributeddesign.eu/.

${ }^{3}$ https://iscapeproject.eu/.

${ }^{4}$ https://www.decidim.barcelona/ and http://superbarrio.iaac.net/.
} 
Poblenou is one of the neighbourhoods situated in the Sant Marti district, an old industrial area in urban regeneration since 17 years, Poblenou is now a mixed place that joins the old and the new, hosts many creative designers and innovative companies while fostering a large ecosystem of cooperatives and social enterprises, an interesting and complex playground for prototyping with the Fab City framework and move towards circular and bioeconomy transitions.

\section{Challenge}

The rise of material flows due to linear supply chain models is critical in urban context. Plastic production and related pollution are no longer viable for sustaining the biodiversity while food waste represents one third of the food present in the supply chain [13]. Waste Management strategies, circular initiatives and new design practices for reducing or designing with food waste are recently seen as great opportunities to better close the loop of systems and create materials from alternative sources that potentially reduce the environmental impact of more conventional materials. This will depend on the fabrication processes and local realities of production and uses. Thus, there is an interest in developing local communities that explore and sustain this new form of craft (neocraft) and manufacturing in a co-creative and responsible way.

The SISCODE journey of IAAC|Fab Lab Barcelona explores the following challenge with an intervention in the neighborhood of Poblenou:

How could co-creation foster the development of innovative ecosystems by

crafting and micro-fabricating with food surplus and waste?

\section{The Co-creation Journey}

\section{Context analysis}

The journey started by analysing the local context and identifying the policies and local ecosystem relating to circular economy, social innovation and urban development. After conducting desk research, participating in 5 public events, conducting 35 interviews, the team gathered a common base of knowledge and future interventions. This preliminary grounding resulted in three outputs: an illustrated timeline of initiative's interviewees, a patchwork of the neighbourhood diversity and a stakeholder mapping based on different models of food value chains and food waste hierarchies.

\section{Problem framing}

To better frame the challenge, the local team has organised an original event to share the first bases of knowledge to a real group of stakeholders of the neighborhood and focus on the effective needs and motivations highlighted by thems. In this first co-creation workshop named "Synergy Soup" ("Sopa de Sinergias"), invited stakeholders took part in creative activities while preparing and eating a soup made with local collected food ingredients. The organisers could collect and discuss 58 needs, 
36 resources and 31 ideas of projects. An interactive categorization of ideas were proposed in an open exhibition in IAAC (The Open Day of Poblenou) where visitors could discover and classify each idea in a matrix that allowed to show and draw how to locally improve material and food cycles at the neighbourhood scale. As a result of those activities, a first group of stakeholders engaged in the co-creation project with five categories of concepts to explore deeper: how to create a collective bank for vegetable seeds and design a Fab Yurt (a mini Fab Lab designed in and for an urban garden)? How to support the local collection of recovered food? How to design with bio-based materials? How to build a library of things? How to promote collective composting?

\section{Envisioning solutions}

To better envision the future solutions while keeping on rising community engagement, the team has organised a series of five 3-h-events that took place in different places of the neighborhood, between the 28th May and 28th June 2019 and that were communicating in a same flyer diffused both online and off-line in restaurants and community places:“¡Haz Comunidad!” (28.05.19), Practicing making (8.06. + 11.06.19), Eco-design and future narratives (18.06.19), convivial agora (28.06.2019).

Those events ranged from ideation sessions with customised tools (like 6Ws, backcasting value opportunity mapping, idea cards, eco-design and scenario building convivial design methods) to learning-by-doing experiences on digital fabrication tools and biomaterial design.

The participants had the opportunities to refine concept proposals, network with other stakeholders and get introduced crafting new materials using different processes.

The events strenghtened connections and enabled the rise of a local symbiotic system model representing each stakeholder with food waste project solutions at the neighbourhood scale. Fructifying from the discussions, the core team could integrate a layer of community services needed to support the development of such systems, consisting in new infrastructures for synergy stimulation, shared learning and design, production and logistics.

The workshop on biomaterial organized by Fabtextiles and based on past researches from the Fabricademy network and aimed at exploring the potential of material innovation from food waste raised a particular attention among the stakeholders that clearly demonstrate an interest in exploring further techniques and social experiences to scale it at the neighborhood scale.

\section{Developing and prototyping}

The prototyping phase started after a reflective summer and a creative phase of planning where the team could publish their initial model and participate in various local events to reconnect with the community members. The governance of the pilot and local team were revised to adjust the new needs for co-production, creating operational internal teams and a more strategic committee at Poblenou's scale.

The prototyping phase went into two main iterations. The first loop was composed of three fuzzy explorative projects: the co-design of a cargo bike $\mathrm{km} 0$, 
the exploration of products based from locally collected eggshells and an awareness campaign endorsing food waste valorisation initiatives. All projects ran in parallel and ended with an open event to showcase the results and ideate on future actions.

In the second loop, the team co-developed and facilitated an incubation programme about circular systems from food waste and surplus. Through an open cal for ideas, the extended co-creation team selected 13 projects, and invited them to start the incubation programme and engage through an agreement with the Fab Lab offering material provision, access to infrastructure, a shared online access, weekly collective session and individual coaching.

With the pandemic context, the program has been extended. It was beneficial both for the team and the participants who could reinforce their cooperation, better finalise their projects and go deeper in the definition of contents and external interventions. It allowed the creation of a series of online events "Remix in conversation", the implementation of individual feedback assessment. The programme ended with a final intervention: the co-design of an exhibition aiming at showcasing their projects and campaign in the barrio to activate new bonds and more awareness about foodwaste-material making. More than 400 people, from newbies to gurus of design, from neighbors to policymakers visited the exhibition which took place in the Leka restaurant [26] following the barrier gestures and necessary restrictions imposed by COVID-19.

\section{The role of policies and policymaker engagement}

Since its initiation 17 years prior, IAAC has collaborated with a wide scope of strategic policy partners in the fields of urbanisation, computerised economy, culture and schooling. Barcelona City Council worked intimately with IAAC and Fab Lab Barcelona through numerous projects to advance new models of development, uphold the maker district backing the Fab City agenda. They worked on the project mode, collaborating according to circonstances and necessities. IAAC does not use formalised methodologies or approaches for connecting with policymakers. Internal dialogs remind primordial to initiate and sustain contacts with policymakers. In the SISCODE pilot, it is impossible to say that they effectively take part actively in the daily co-creation activities, however they had impacted the process or encouraged the team. The team realised that the presence or absence of policymakers associated as direct partners in such co-creation projects has a direct influence on their involvement.

Facing the difficulties to directly engage them in co-creation activities, IAAC team used more indirect strategies to reach them and benefit from their feedback and support. Here the most impactful ones:

- Conducting informal interviews with civil servants in the early stage of the process

- Be aware and active in local political events

- Create a climate of mutual trust to facilitate direct logistics and communication

- Co-organising activities and events led by the city (beyond the label of service providers)

- Applying for city funding and local communication calls. 
Finally, the team has created a policy brief at the end of the project in the format of a manifiesto to communicate the recommendations of the collective Remix El Barrio for the design of future policies on scaling circular ecosystem crafting and micro-fabricating with food waste. This document has been transmitted to local and european stakeholders via direct mailing, catalogue online diffusion and diffusion in social media.

\section{Experimentation: Output, Transformations, Outcomes}

Remix El Barrio is now a collective of designers who propose projects with food leftovers using artisan techniques and digital manufacturing. They collaborate with agents from the Poblenou neighborhood to foster a more local and circular ecosystem. 9 main projects were developed: Kofi developed proposed to make paper and packaging from coffee waste; Naifactory and En(des)uso is creating lamps, chairs and pots from olive pits, eggshells, mate; Squeeze the Orange has designed an entire jacket made with orange peels; Colores is creating natural dyeing from avocado pits; Dulce de Piel is designing soap from used oils; Look Ma No Hand and Circular Gos are cooking snacks respectively for neighbors and dogs from restaurant leftovers.

Remix El Barrio is more than the sum of individual projects mentorised by the Fab Lab. Members are united around the values of local cooperation, solidarity, new form of crafts and circularity in Barcelona. They are supporting each other, campaigning together and co-producing a set of new experiences.

Beyond two research publications [19, 22], three main outputs were recently co-created: the design of exhibitions and its catalogues in two languages, ${ }^{5}$ the development of video tutorials ${ }^{6}$ and the co-elaboration of Gitbook ${ }^{7}[3,23,24]$. The initiative were awarded as Grand Prize for Innovative Collaboration by the Starts Prize $2021[28]$.

The exhibition "Remix El Barrio-Co-design of biomaterials from food leftovers in Poblenou" first took place from 14.10.2019 to 23.10.2020 in the open source Restaurant LEKA [26]. It contains the nine projects accompanied by other artefacts of the SISCODE co-creation journey, a special creation from the Fabricademy, locally crafted labels and posters. The exhibition benefit from the visibility of the Fab City Summit,${ }^{8}$ the Poblenou Urban District open day/night, ${ }^{9}$ the Foodture event ${ }^{10}$ and the local FOOD SHIFT pilot kick-off ${ }^{11}[7,11,12,20]$. The exhibition has been

\footnotetext{
${ }^{5} \mathrm{https}: / /$ issuu.com/iaac/docs/remix_el_barrio_catalogo_en_1_compressed.

${ }^{6}$ https://www.youtube.com/playlist?list=PL33KKs9g8Y1K4MJGAUHpMZn-wMcbOVhnV.

${ }^{7}$ https://flbcn.gitbook.io/remix-el-barrio/.

${ }^{8}$ https://fablabbcn.org/calendar/fabcitysummit2020.

${ }^{9} \mathrm{https} / / / \mathrm{www}$.poblenouurbandistrict.com/es/category/poblenou-urban-district/podn12h/.

${ }^{10} \mathrm{http}: / / \mathrm{www}$. foodture.barcelona/.

${ }^{11}$ https://foodshift2030.eu/labs/food-tech-3-0-lab/.
} 
replicated from March to May 2021 in the design hub of Barcelona in collaboration with Materfad [17] and the attendance of more 1000 visitors.

In times of COVID-19, online tutorials appeared as a relevant media to transmit practical hands-on knowledge. Fab Lab Barcelona Communication's team has collaborated with the team of Remix El Barrio to shoot and edit a set of 9 trial videos reviewing biomaterial recipes step by step from preparation, cooking and use.

The book describes the narratives of the co-creation journey, presents the 9 key design projects and associated educational materials such as a map of interactions with business models and emergent future stories, presents a list of tips, tools, recipes, courses, and protocols to better develop educational and incubation programs.

The team of IAAC|Fab Lab Barcelona experienced new learnings on co-creation and became more familiar with the respective processes and competences needed to apply it in a more structured way for long term projects. The co-creation lab has made explicit and challenged ongoing practices about stakeholder engagement, design processes, lab management, communication, policy context analysis.

Internally, the co-creation lab has contributed to the structuration of a circular community expertise and the creation of knowledge crossing the strategic areas of productive cities and Material and Textiles. It occured at the same time that many organisational changes in Fab Lab Barcelona. The core team members could learn about the agile environment and benefit of time to reflect on those practices dialoguing with SISCODE partners.

In terms of stakeholder engagement, it can be said that Remix El Barrio engaged with a dense network of stakeholders from local to global community. It is interesting to highlight the position of the lab as an interface between the members of the collective, the local community partners and the distributed networks, allowing synergy making, knowledge and technological infrastructure sharing and project incubation. The stakeholder management process is echoing with ongoing models and practices developed within the distributed design communities while really giving value to the importance of "real-time" situated supports, interaction and attitudes.

Beyond SISCODE, the team is now offering a panel of approaches not only to integrate circular principles and projects in existing global Fab Lab academies, but also to sustain circular community engagement locally and provide service support at the city scale destined to policymakers, makerspaces, civil society, industrials. As an example, it can be mentioned the Pop Machina Circular Maker Academy, ${ }^{12}$ the development of new Fab City Hub open to public, new local collaborations about biomaterial like Remix the School, ${ }^{13}$ new training, incubation and acceleration programs elaborated through EU projects (FoodShift, Centrinno, Shemakes) $[21,25,27]$.

\footnotetext{
12 https://fablabbcn.org/projects/pop-machina.

${ }^{13}$ https://fablabben.org/projects/remix-the-school.
} 


\section{Lessons Learnt and Reflections}

This co-creation journey was a rich learning journey for the participants who could have the chance to experience the benefit of research-action, distributing their time between local co-creation management, activity design and reflective moments with the SISCODE consortium.

The co-creation process also conducted the project members to envision and test a set of indicators to monitor circular community projects emphasising the importance of demonstrating the changes of material flows, being transparent about the state of environmental impact analysis, commenting the learning curves and cross-pollination of knowledge between members, showing the effective interactions between stakeholders and expliciting honestly the capacity of the lab infrastructure to respond to the local needs.

The team entered into the intimacy of the co-creation processes and could have faced many complex situations. Some lessons learnt from this particular case could be noted:

- Co-creation is about creating safe and accessible learning spaces to ensure people have trust in themself, rising autonomy, regardless of their profiles or expertise, while connecting them with ideas and realities, proposing innovative forms of dialoguing with uncertain futures.

- Facilitating co-creation in Labs come with many soft skills to acquire and could benefit from various profiles such as the "gurus", technical experts passionate about making, systemic designers acting as interfaces between people, design artefacts and new policies and community managers that have a natural sense of connecting with people embedded in the local territory.

- Co-creation processes are value-centred. The Remix collective all shares the common motivation to create positive changes, rethinking how to better cocreate "commons" through knowledge cross-pollination and learning by doing philosophy, and caring, by being curious and caring about others.

Co-creation is about dealing with creativity, uncertainties and tensions. Constant efforts are being done to reframe the action, maintain the cohesion, dialoguing about potential doubts of participants. Pollinating co-creation processes such as the ones initiated through the Siscode project (letting open spaces for expressing common aspirations and concerns has a strong role in better engaging with citizens and overcoming tensions present in territorial dynamics.

\section{References}

1. Agència de Residus de Catalunya_Food waste. http://residus.gencat.cat/en/ambits_dactuacio/ prevencio/malbaratament_alimentari. Last accessed 2021/03/29

2. Climate Plan BCN-Climate Plan 2018-2030. https://www.barcelona.cat/barcelona-pelclima/sites/default/files/documents/climate_plan_maig.pdf. Last accessed 2021/03/29 
3. Co-Design with biomaterials from food leftovers in Poblenou-Exhibition catalogue. https://issuu.com/iaac/docs/remix_el_barrio_catalogo_en_1__compressed. Last accessed $2021 / 03 / 29$

4. Decidim.barcelona. https://www.decidim.barcelona/. Last accessed 2021/03/29

5. Diez T (2018) Fab City Whitepaper Locally productive, globally connected self-sufficient cities Available at: https://fab.city/documents/whitepaper.pdf. Last accessed 2020/06/28

6. Distributed Design Market Platform, https://distributeddesign.eu/. Last accessed 2021/03/29

7. Distributed fab City Summit 2020. https://fablabbcn.org/calendar/fabcitysummit2020. Last accessed 2021/03/29

8. European Commission: A sustainable Bioeconomy for Europe: strengthening the connection between economy, society and the environment. Brussels (2018) https://ec.europa.eu/research/ bioeconomy/pdf/ec_bioeconomy_strategy_2018.pdf. Last accessed 2020/06/26

9. Fabricademy. https://textile-academy.org/. Last accessed 2021/06/23

10. Fabtextiles. http://fabtextiles.org/. Last accessed 2021/06/23

11. FoodTech 3.0 Lab-Food Shift. https://foodshift2030.eu/labs/food-tech-3-0-lab/. Last accessed 2021/03/29

12. Foodture Barcelona. http://www.foodture.barcelona/. Last accessed 2021/03/29

13. Gustavsson J, Cederberg C, Sonesson U, Van Otterdijk R, Meybeck A (2011) Global food losses and food waste. Global food losses and food waste-extent, causes and prevention. Rome, available at https://www.madr.ro/docs/ind-alimentara/risipa_alimentara/presentation_ food_waste.pdf. Last accessed 2020/08/25

14. Iscape, p-Improving the Smart Control of Air Pollution in Europe, https://www.iscapeprojec t.eu/. Last accessed 2021/03/29

15. Les cooperatives obreres de Sants [Libro], https://www.freepress.coop/les-cooperatives-obr eres-de-sants-libro/. Last accessed 2021/03/29

16. Making Sense EU, http://making-sense.eu/. Last accessed 2021/03/29

17. Materfad. https://www.fad.cat/materfad/es. Last accessed 2021/06/23

18. OECD (2020) The circular economy in cities and regions: synthesis report. OECD Urban Studies. OECD Publishing, Paris

19. Pistofidou A, Real M, Juarez Calvo M (2020) Remix El Barrio: a co-creation journey to foster innovative ecosystems crafting and micro-fabricating with food surplus and waste. Creative Food Cycles-Book 1:185-195

20. Poblenou Urban District. https://www.poblenouurbandistrict.com/es/category/poblenouurban-district/podn12h/. Last accessed 2021/03/29

21. Pop-Machina - FabLab BCN. https://fablabben.org/projects/pop-machina. Last accessed 2021/03/29

22. Real M, Calvo M (2019) Boosting co-creation practices in makespaces to support the design of more empowering and circular food systems at a neighbourhood scale. In: Proceedings of the 19th European roundtable for sustainable consumption and production circular, vol 1, Spain. ISBN 978-84-09-16892-7, pp 831-840

23. Remix el Barrio-Biomaterials Recipe Videos. https://www.youtube.com/playlist?list=PL3 3KKs9g8Y1K4MJGAUHpMZn-wMcbOVhnV. Last accessed 2021/03/29

24. Remix el Barrio-Gitbook. https://flben.gitbook.io/remix-el-barrio/. Last accessed 2021/03/29

25. Remix the school-FabLab BCN. https://fablabbcn.org/projects/remix-the-school. Last accessed 2021/03/29

26. Restaurant Leka, Barcelona. https://restauranteleka.com/. Last accessed 2021/03/29.

27. SheMakes_FabLab BCN. https://fablabbcn.org/projects/shemakes. Last accessed 2021/03/29

28. Starts Prize. https://starts-prize.aec.at/en/. Last accessed 2021/06/23

29. Woods M, Balestrini M, Bejtullahu S, Bocconi S, Boerwinkel G, Boonstra M, Boschman D-S, Camprodon G, Coulson S, Diez T, Fazey I, Hemment D, van den Horn C, Ilazi T, Jansen-Dings I, Kresin F, McQuillan D, Nascimento S, Pareschi E, Polvora A, Salaj R, Scott M, Seiz G, Fazey I (2018) Citizen sensing: a toolkit 
Open Access This chapter is licensed under the terms of the Creative Commons Attribution 4.0 International License (http://creativecommons.org/licenses/by/4.0/), which permits use, sharing, adaptation, distribution and reproduction in any medium or format, as long as you give appropriate credit to the original author(s) and the source, provide a link to the Creative Commons license and indicate if changes were made.

The images or other third party material in this chapter are included in the chapter's Creative Commons license, unless indicated otherwise in a credit line to the material. If material is not included in the chapter's Creative Commons license and your intended use is not permitted by statutory regulation or exceeds the permitted use, you will need to obtain permission directly from the copyright holder.

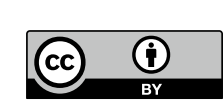

